\title{
Impact of continuing medical education in cancer diagnosis on GP knowledge, attitude and readiness to investigate - a before-after study
}

Berit Skjødeberg Toftegaard ${ }^{1,2,3^{*}}$, Flemming Bro ${ }^{1,3}$, Alina Zalounina Falborg ${ }^{1,2,3}$ and Peter Vedsted ${ }^{1,2,3}$

\begin{abstract}
Background: Continuing medical education (CME) in earlier cancer diagnosis was launched in Denmark in 2012 as part of the Danish National Cancer Plan. The CME programme was introduced to improve the recognition among general practitioners (GPs) of symptoms suggestive of cancer and improve the selection of patients requiring urgent investigation. This study aims to explore the effect of CME on GP knowledge about cancer diagnosis, attitude towards own role in cancer detection, self-assessed readiness to investigate and cancer risk assessment of urgently referred patients.
\end{abstract}

Methods: We conducted a before-after study in the Central Denmark Region including 831 GPs assigned to one of eight geographical clusters. All GPs were invited to participate in the CME at three-week intervals between clusters. A questionnaire focusing on knowledge, attitude and clinical vignettes was sent to each GP one month before and seven months after the CME. The GPs were also asked to assess the risk of cancer in patients urgently referred to a fast-track cancer pathway during an eight-month period. CME-participating GPs were compared with reference (non-participating) GPs by analysing before-after differences.

Results: One quarter of all GPs participated in the CME. 202 GPs (24.3\%) completed both the baseline and the follow-up questionnaires. 532 GPs (64.0 \%) assessed the risk of cancer before the CME and 524 GPs (63.1 \%) assessed the risk of cancer after the CME in urgently referred consecutive patients. Compared to the reference group, CME-participating GPs statistically significantly improved their understanding of a rational probability of diagnosing cancer among patients urgently referred for suspected cancer, increased their knowledge of cancer likelihood in a 50-year-old referred patient and lowered the assessed risk of cancer in urgently referred patients.

Conclusions: The standardised CME lowered the GP-assessed cancer risk of urgently referred patients, whereas the effect on knowledge about cancer diagnosis and attitude towards own role in cancer detection was limited. No effect was found on the GPs' readiness to investigate. CME may be effective for optimising the interpretation of cancer symptoms and thereby improve the selection of patients for urgent cancer referral.

Trial registration: NCT02069470 on ClinicalTrials.gov. Retrospectively registered, 1/29/2014.

Keywords: Denmark, General practice, Continuing medical education, Diagnosis, Early detection of cancer, Knowledge, Attitude, Readiness to investigate, Risk assessment

\footnotetext{
* Correspondence: berit.toftegaard@feap.dk

${ }^{1}$ Research Unit for General Practice, Department of Public Health, Aarhus

University, Bartholins Allé 2, DK-8000 Aarhus, Denmark

${ }^{2}$ Research Centre for Cancer Diagnosis in Primary Care (CaP), Department of

Public Health, Aarhus University, Bartholins Allé 2, DK-8000 Aarhus, Denmark

Full list of author information is available at the end of the article
} 


\section{Background}

Increasing evidence indicates that timely detection can improve cancer survival [1-3]. Urgent referral to cancer investigation was established in Denmark in 2008 [4], but successful effect of such initiative depends on the patient referral patterns in general practice. As $85 \%$ of cancer patients initially present symptoms to their general practitioner (GP) $[3,5]$, timely referral may be improved by optimising the GPs' recognition and interpretation of symptoms as this might lead to earlier diagnosis of cancer. A major challenge for the GP is that most of the symptoms which could signal cancer have a benign cause [6]. Each time such a patient is seen in consultation, the GP must evaluate the risk of cancer, consider the need for investigations and assess the degree of urgency [7]. Therefore, the GP operates under an integrated risk model which considers both basis risk (e.g. patient age, gender and family history) and added risk (e.g. presence or absence of symptoms, clinical findings and test results) [8]. The latest Danish national cancer plan, which was adopted in 2012, launched a continuing medical education (CME) programme in earlier cancer diagnosis to support and further develop the GPs' decision-making strategies for referral. A specific CME intervention was developed [9] and implemented based on the available evidence [10-12]. The CME focused on several issues, including the diagnostic process in general practice, symptom risk assessment tools (RATs) [13, 14] and risk of false reassurance when interpreting the results of chest X-rays [15, 16] and gynaecological examinations [14].

Enhanced knowledge may provide improved understanding of diagnosing cancer, which may change the GP's attitude towards own role in cancer detection. Still, attitudes and readiness to investigate are also influenced by the cultural settings and the organisational system in which the GP operates as a gatekeeper to secondary care $[17,18]$. However, to our knowledge, no former studies have measured the effect of a specific CME on knowledge, attitude and intentions in the same study, with the same GP participants and intervention.

The aim of this study was 1) to analyse the effect of a standardised CME in earlier cancer diagnosis on the GPs' knowledge about cancer diagnosis and 2) to assess the GPs' attitudes towards own role in cancer detection. We also intended 3) to analyse whether the CME changed the GPs' self-assessed readiness to investigate hypothetical symptomatic patients and 4) to assess the impact of the CME on the GPs' cancer risk assessment of patients urgently referred for cancer suspicion.

\section{Methods}

\section{Setting}

The study was performed in one of five Danish regions, the Central Denmark Region, with 1.27 million inhabitants, 417 general practices and 831 GPs. In Denmark, GPs own their own practice and operate under a publicly funded mixed remuneration scheme based on a collective agreement with the Danish regions [19]. All GPs have a contract with the public health insurance, which ensures more than $90 \%$ of their earnings. Part of the agreement includes remuneration for participation in CME. Most citizens (98 \%) are listed with a specific general practice, and the GP must first be consulted if a citizen needs (free) medical advice, except for emergencies. Therefore, GPs act as gatekeepers to hospitals and private specialists.

\section{Intervention: continuing medical education}

The planning of the CME was initiated by a multidisciplinary team. A working group was established to operationalise the CME, which has been described elsewhere [9]. The CME consisted of a 3-h session with a multifaceted teaching approach [12]. The key aim of the CME was to optimise cancer-related referrals from general practice to hospitals by reducing the GPs' referral threshold and to increase their knowledge about cancer symptoms in an attempt to identify underlying cancers at an earlier stage. Barriers on GP-level were addressed in a reflective debate among the GPs [9]. All GPs were provided with the available risk assessment charts on lung, colorectal, ovarian and prostate cancer [13, 14]. However, the CME focused on earlier detection of all cancer types. The CME was conducted by a team of six persons with different health-care backgrounds [9].

\section{Overall study design and recruitment of GPs}

To increase CME attendance, geographical accessibility was ensured by conducting eight local meetings. All GPs in the region were assigned to one of eight clusters based on geography. All GP clusters were invited to the CME in the period of September 2012 to May 2013 with 3-week intervals. The Regional Cancer Quality Unit decided the random order in which the clusters were offered the CME intervention. The CME was announced by mail invitations two months and again one month before the CME was planned to take place. Each GP was registered upon arrival at the CME [9]. We performed a before-after study embedded in a stepped-wedge enrolment of the CME intervention.

\section{Questionnaire data}

GPs who had already responded to a similar questionnaire (International Cancer Benchmarking Partnership study, module-3 (ICBP-M3)) [20] in September 2012 were excluded, and 751 GPs were invited to complete the baseline questionnaire. The GPs received an e-mail invitation with a link to the online survey one month before their CME was scheduled to take place. GPs who 
responded to the baseline survey were invited to complete the follow-up questionnaire seven months after their CME date. Reminders were sent to nonrespondents 14 days after the primary invitation in both surveys. Remuneration was 33 euros for completing the baseline questionnaire and 17 euros for completing the follow-up questionnaire.

The online questionnaire consisted of single items and vignettes. The items were developed based on the elements included in the CME to measure the CME effect on knowledge about cancer diagnosis (6 items), attitude towards own role in cancer detection (7 items) and attitude towards practical aspects of urgent referral [9]. The vignettes were validated and tested in the ICBP-M3 project [20]. They measured readiness to investigate when a hypothetical patient presented with symptoms suggestive of lung cancer (two vignettes), colorectal cancer (two vignettes) or ovarian cancer (one vignette). The English versions of the vignettes were translated into Danish [9].

\section{GP knowledge}

GP knowledge about cancer diagnoses comprised 1) cancer as a condition with a low prevalence (one item), 2) positive predictive values (PPVs) for cancer of selected symptoms (two items), 3) diagnostic pitfalls (two items) and 4) initial cancer presentation (one item). The wording of each item initiated with "what is the likelihood that..." or "what is the proportion of..." and the GP was requested to state the response as a percentage (0-100\%). Based on the available evidence, the research group agreed on the most appropriate response (MAR) test area as a percentage range for each of the six items (Additional file 1).

\section{GP attitude}

The GP's attitude towards own role in cancer detection, which is related to the GP's interpretation of the balance between benefits and harms of early diagnostic testing, was measured by statements addressing the concerns about 1) overusing healthcare services or distressing the patient when an urgent referral does not result in a cancer diagnosis (two items), 2) risking over-diagnosis when ordering tests (one item), 3) communicating cancer risk with patient and fast-track coordinator (two items) and 4) exploring the GP's referral threshold for urgent cancer investigation (two items). The GP's attitude towards practical aspects of urgent referral was measured by statements addressing the GP's experience with 1) use of urgent referral (complicated and/or time-consuming), 2) delivery of written patient instructions and 3) use of information from the online cancer guideline. Responses were given on a 5 -point Likert scale. The research group agreed to dichotomise the responses for each attitude item based on the two most appropriate responses (i.e. agree/strongly agree) versus the remaining three response options including neutral.

\section{GP readiness to investigate}

The GPs were presented with two randomly chosen vignettes at baseline and another two vignettes at follow-up. Each vignette included a description of a patient's initial symptom presentation and asked the GP to decide which action to take. If the GP chose an expectant strategy, the case developed further and the patient returned with new and more severe symptoms [20] (Additional file 2).

\section{GP cancer risk assessment of urgently referred patients}

All 831 GPs in the Central Denmark Region received a pad with 25 one-page forms. The GPs were requested to complete a form each time a patient was urgently referred for suspected cancer $[9,21]$ during an 8-month period (1 September 2012-1 May 2013). Patients investigated in a fast-track pathway were also identified in the patient administrative system for hospital care. If the GP form was missing for a patient identified in the register, the GP received a form for that particular patient and was requested to complete it.

The form included information about the patient's personal identification number, the date of referral and the GP's assessment of the patient's risk of cancer (0-100 \%) at the time of the referral [9]. Remuneration was 100 euros for completion of forms during the 8-month period. The form was processed using Teleform Version 8.0 (Cardiff Software Inc., San Marcos, CA, USA). Handwritten data were coded by the first author (BST) before scanning [22]. All optically scanned data were checked for outliers and discrepancies.

\section{Analyses}

GPs were divided into a CME-participating group and a non-participating reference group. The time point for a CME-session was identical with the point for crossover from before to after, and thus it constituted a step in the before-after models. Data were collected before and after the CME to provide paired responses for each outcome variable. GP characteristics were described for the entire study base, for the GPs who completed baseline and follow-up surveys and for GPs who assessed cancer risk in referred patients.

Responses to attitude and knowledge items were presented as proportions of the GPs who responded most appropriately (Additional File 1 for knowledge items). Attitude and knowledge levels before and after CME were compared within and between groups by conditional fixed-effects Poisson regression based on cluster-robust standard errors (SEs). Within-individual differences were used to estimate effects, and each GP was used as own control. We used the robust SEs to relax the assumption 
behind the Poisson model that the variance was equal to the mean [23]. The SEs were corrected for clustering at step level. Effects within groups were reported as risk ratios (RRs). Comparison of effects between groups was reported as a ratio of RRs.

GP readiness to investigate was analysed through the proportions of vignettes where the GP made a definitive action after first and after second phase. Because of the binary data format, comparisons of responses before and after CME were performed by using multilevel mixedeffects logistic regression to ensure that within-GP correlations were taken into account [24]. The model allowed for random effects at GP level. The time of observation (before and after CME) was treated as a fixed-effect variable. The effects within groups were reported as odds ratios (ORs). Comparison of effects between groups was reported as a ratio of the ORs. The analyses were adjusted for study step and type of vignette.

GP cancer risk assessment of urgently referred patients was described as mean risk with $95 \%$ confidence interval (CI) and median with interquartile interval (IQI), as the population was not normally distributed. Comparisons of risk assessment before and after CME within and between groups were performed using multilevel mixed-effects linear regression. The model was fitted to take into account within-GP correlations and GP clustering in clinics. The time of observation (before and after CME) was treated as a fixed effect variable. To satisfy the assumptions of the model and be able to compare mean risks, the dependent variable was square root transformed. The analyses were adjusted for study step, patient gender and patient age.

All statistical analyses were performed using Stata software version 13.0 (StataCorp LP, College Station, TX, USA).

\section{Results}

\section{Study population}

The study base consisted of 831 GPs (Table 1). A total of 197 GPs (23.7 \%) participated in the CME; they did not differ from the study base in age, but the CMEparticipating GPs were less likely to be male and solo GPs. Baseline and follow-up questionnaires were completed by 202 GPs $(24.3 \%)$. Of these, the CMEparticipating GPs were younger, less likely to be male and solo GPs, whereas reference GPs were younger, less likely to be female, but they did not differ in clinic type from the study base (Table 1). Due to technical difficulties with the online survey, 6 GPs were not able to complete both baseline and follow-up vignettes and were excluded from the vignette analyses (Fig. 1).

Cancer risk assessment of urgently referred patients was completed by 532 GPs (64.0\%) before the CME and 524 GPs (63.1\%) after the CME. The CME-participating GPs were less likely to be male and solo GPs, but did not differ in age, whereas the reference GPs did not differ in age, gender and clinic type compared to the study base (Table 1).

Table 1 Characteristics of GPs. Age, gender and type of clinic are shown for all GPs in the Central Denmark Region (study base), GPs responding to the knowledge and attitude questionnaire, GPs completing the vignettes and GPs assessing risk of cancer for continuous patients. GPs are divided into the CME-participating GPs and the reference GPs

\begin{tabular}{|c|c|c|c|c|}
\hline & \multirow[b]{2}{*}{$N(\%)$} & \multicolumn{3}{|l|}{ GP characteristics } \\
\hline & & $\begin{array}{l}\text { Mean age Years } \\
(95 \% \mathrm{Cl})\end{array}$ & $\begin{array}{l}\text { Proportion of males \% } \\
(95 \% \mathrm{Cl})\end{array}$ & $\begin{array}{l}\text { Proportion of solo GPs } \% \\
(95 \% \mathrm{Cl})\end{array}$ \\
\hline \multicolumn{5}{|l|}{ Study base } \\
\hline Total & $831(100)$ & $52.3(51.7 ; 52.8)$ & $54.3(50.9 ; 57.7)$ & $24.1(21.2 ; 27.0)$ \\
\hline Reference GPs & $634(76.3)$ & $52.4(51.7 ; 53.0)$ & $56.5(52.6 ; 60.3)$ & $26.0(22.6 ; 29.4)$ \\
\hline CME-participating GPs & $197(23.7)$ & $51.9(50.8 ; 53.0)$ & $47.2(40.2 ; 54.2)$ & $17.8(12.4 ; 23.2)$ \\
\hline \multicolumn{5}{|c|}{ GPs that completed knowledge and attitudes items } \\
\hline Reference GPs & $121(19.1)$ & $49.8(48.3 ; 51.4)$ & $57.9(48.9 ; 66.8)$ & $24.0(16.3 ; 31.7)$ \\
\hline CME-participating GPs & $81(41.1)$ & $50.7(48.8 ; 52.5)$ & $46.9(35.8 ; 58.0)$ & $18.5(9.9 ; 27.2)$ \\
\hline \multicolumn{5}{|l|}{ GPs that completed vignettes } \\
\hline Reference GPs & $116(18.3)$ & $49.9(48.4 ; 51.5)$ & $58.6(49.5 ; 67.7)$ & $23.3(15.5 ; 31.1)$ \\
\hline CME-participating GPs & $80(40.6)$ & $50.5(48.7 ; 52.4)$ & $47.5(36.3 ; 58.7)$ & $18.8(10.0 ; 27.5)$ \\
\hline \multicolumn{5}{|c|}{ GPs that assessed risk of cancer on urgently referred patients } \\
\hline Reference GPs, before & $384(60.6)$ & $51.6(50.8 ; 52.4)$ & $52.6(47.6 ; 57.6)$ & $26.8(22.4 ; 31.3)$ \\
\hline Reference GPs, after & $364(57.4)$ & $51.7(50.8 ; 52.6)$ & $53.6(48.4 ; 58.7)$ & $22.3(18.0 ; 26.5)$ \\
\hline CME-participating GPs, before & $148(75.1)$ & $51.6(50.3 ; 52.9)$ & $45.9(37.8 ; 54.1)$ & $17.6(11.4 ; 23.8)$ \\
\hline CME-participating GPs, after & $160(81.2)$ & $51.9(50.6 ; 53.1)$ & $46.9(39.1 ; 54.7)$ & $15.6(9.9 ; 21.3)$ \\
\hline
\end{tabular}




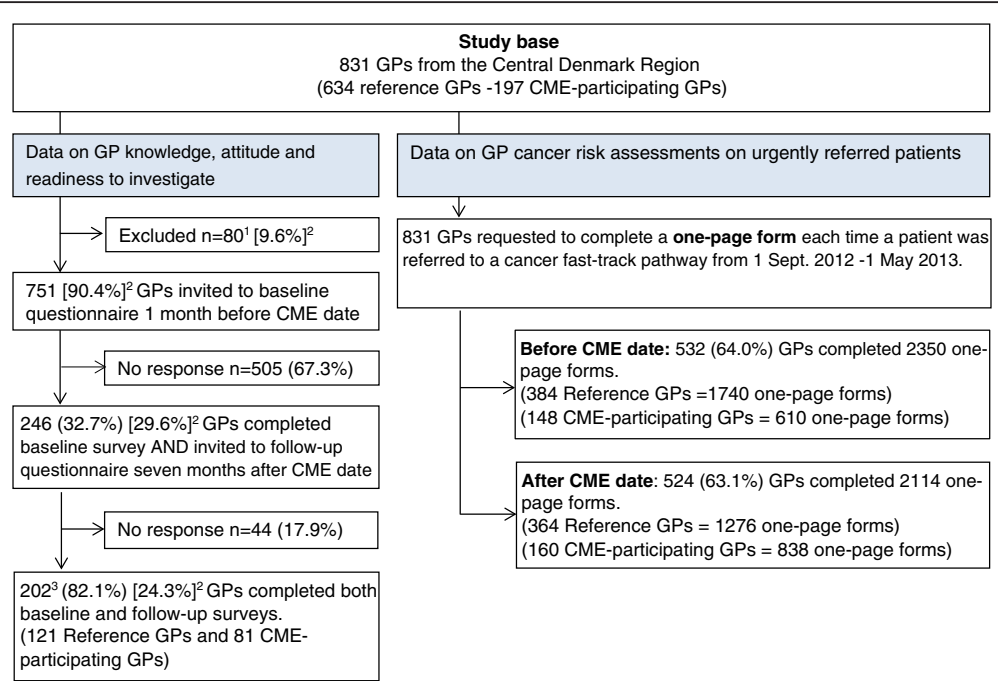

Fig. 1 Flowchart of the data collection. The left part illustrates the GP completion of questionnaires at baseline (1 month before the CME) and at follow-up (7 months after the CME). The right part illustrates the consecutive GP completion of one-page forms, including assessed risk of cancer in referred patients before and after the CME. 'GPs who completed a similar questionnaire in the ICBP study, module 3, September 2012. ${ }^{2}$ Proportion of study base. ${ }^{3} 196$ GPs completed both baseline and follow-up vignettes (116 reference GPs and 80 CME-participating GPs). 6 GPs were lost to follow-up due to a technical failure of the online survey system

\section{CME effect on GP attitude}

The CME-participating GPs showed a statistically significant appropriate change in 2 of 7 items addressing the attitude towards own role in cancer detection compared to the reference GPs (Table 2). After the CME, the participating GPs were more likely to disagree with the following two statements: 'If a patient referred by me to a cancer fast-track pathway turns out not to have cancer, unnecessary strain has been placed on the patient' and 'The more of the patients referred by me to a cancer fast-track pathway turn out to have cancer, the better a doctor I am'.

No differences were found for the 6 items addressing attitude towards practical aspects of urgent referral for suspected cancer (not reported in table).

\section{CME effect on GP knowledge about cancer diagnosis}

The CME-participating GPs showed a statistically significant appropriate change in only 1 out of 6 items addressing GP knowledge about cancer diagnosis compared to the reference GPs. They increased their knowledge regarding the likelihood that a patient aged 50 would have cancer at the time of urgent referral (Table 3). Although not significantly, the CMEparticipating GPs tended to have increased knowledge compared to the reference GPs on the likelihood that a patient aged 40 and above would have colorectal cancer the first time the patient presented unintended weight loss and newly onset constipation in general practice (Table 3).

\section{CME effect on GP readiness to investigate (vignettes)}

The proportion of vignettes where GPs made a definitive action at the end of the second phase has been significantly increased within the CME-participating group, but no significant differences in before-after changes in self-assessed readiness to investigate were found between the two groups (Table 4).

\section{CME effect on GP cancer risk assessment of urgently referred patients}

The CME-participating GPs statistically significantly lowered their assessed risk of cancer in urgently referred patients compared to the reference GPs (Table 5).

\section{Discussion}

\section{Main findings}

We found that one fourth of the GPs participated in a CME on earlier cancer diagnosis. The standardised CME lowered the GP-assessed cancer risk of urgently referred patients and showed a limited effect on the GPs' knowledge about cancer diagnosis and attitude towards own role in cancer detection. The CME had no effect on the GPs' self-assessed readiness to investigate or the GPs' attitude towards practical aspects of urgent referral.

\section{Strength and limitations}

The before-after design with geographical clusters of GPs receiving CME in a random order three weeks a part made it possible to perform a robust evaluation with correction for baseline measures of a rather 
Table 2 The CME effect on GPs' attitude towards own role in cancer detection. The proportion of GPs responding most appropriately is shown for each of the items; one month before (Before) and seven months after (After) the CME. GPs are divided into two groups: CME-participating group and reference group. An effect within a group is shown as a risk ratio (RR0 for the Reference group; RR1 for the CME-participating group). Comparisons between groups are shown as ratio of risk ratios (RR1/RRO)

\begin{tabular}{|c|c|c|c|c|c|c|c|c|}
\hline & \multirow{4}{*}{ Most appropriate answers } & \multicolumn{3}{|c|}{ Reference group } & \multicolumn{3}{|c|}{ CME-Participating group } & \multirow{4}{*}{$\begin{array}{l}\text { Comparison } \\
\text { between } \\
\text { groups } \\
\text { RR1/RRO }\left(p^{*}\right)\end{array}$} \\
\hline & & \multicolumn{3}{|l|}{$N=121$} & \multicolumn{3}{|l|}{$N=81$} & \\
\hline & & Before & After & $\overline{\text { Before vs. after }}$ & Before & After & $\overline{\text { Before vs. after }}$ & \\
\hline & & $\%(n)$ & $\%(n)$ & $\operatorname{RRO}\left(p^{*}\right)$ & $\%(n)$ & $\%(n)$ & RR1 $\left(p^{*}\right)$ & \\
\hline $\begin{array}{l}\text { If a patient referred by me to a cancer } \\
\text { fast-track pathway turns out not to } \\
\text { have cancer, it is overuse of health } \\
\text { services. }\end{array}$ & Strongly disagree - disagree & $86.8(105)$ & $84.3(102)$ & $0.97(0.419)$ & $81.5(66)$ & $87.7(71)$ & $1.08(0.163)$ & $1.11(0.241)$ \\
\hline $\begin{array}{l}\text { If a patient referred by me to a cancer } \\
\text { fast-track pathway turns out not to } \\
\text { have cancer, unnecessary strain has } \\
\text { been placed on the patient. }\end{array}$ & Strongly disagree - disagree & $83.5(101)$ & $79.3(96)$ & $0.95(0.221)$ & $75.3(61)$ & $79.0(64)$ & $1.05(0.275)$ & $1.11(<0.001)$ \\
\hline $\begin{array}{l}\text { The more of the patients referred by } \\
\text { me to a cancer fast-track pathway } \\
\text { turn out to have cancer, the better } \\
\text { a doctor I am. }\end{array}$ & Strongly disagree - disagree & $57.9(70)$ & $62.0(75)$ & $1.07(0.224)$ & $59.3(48)$ & $79.0(64)$ & $1.33(\mathbf{0 . 0 0 3})$ & $1.24(\mathbf{0 . 0 1 3 )}$ \\
\hline $\begin{array}{l}\text { I am a good doctor when I refer a } \\
\text { patient to a cancer fast-track } \\
\text { pathway based on a reasonable } \\
\text { suspicion, as it quickly clarifies } \\
\text { the suspicion. }\end{array}$ & Strongly agree- agree & $81.0(98)$ & $81.8(99)$ & $1.01(0.823)$ & $86.4(70)$ & $82.7(67)$ & $0.96(0.397)$ & $0.95(0.537)$ \\
\hline $\begin{array}{l}\text { I am reluctant to order tests } \\
\text { because of the risk of } \\
\text { over-diagnosis. }\end{array}$ & Strongly disagree - disagree & $75.2(91)$ & $75.2(91)$ & $1.00(1.000)$ & $71.6(58)$ & $75.3(61)$ & $1.05(0.308)$ & $1.05(0.314)$ \\
\hline $\begin{array}{l}\text { I find it hard to mention cancer } \\
\text { suspicion to a patient with } \\
\text { alarm symptoms of cancer. }\end{array}$ & Strongly disagree - disagree & $81.0(98)$ & $83.5(101)$ & $1.03(0.402)$ & $74.1(60)$ & $75.3(61)$ & $1.02(0.704)$ & $1.00(0.813)$ \\
\hline $\begin{array}{l}\text { I feel well prepared to } \\
\text { communicate with the } \\
\text { cancer pathway coordinators. }\end{array}$ & Strongly agree- agree & $82.6(100)$ & $78.5(95)$ & $0.95(0.224)$ & $79.0(64)$ & $77.8(63)$ & $0.98(0.806)$ & $1.03(0.697)$ \\
\hline
\end{tabular}

Bold $=$ significance level of $p \leq 0.05$. *corrected for clustering at the study-step-level 
Table 3 The CME effect on GPs' knowledge about cancer diagnosis. The proportion of GPs responding most appropriately (MAAA) is shown for each item; one month before (Before) and seven months after (After) the CME. GPs are divided into two groups: CME-participating group and reference group. An effect within a group is shown as a risk ratio (RRO for the Reference group; RR1 for the CME-participating group). Comparisons between groups are shown as ratio of risk ratios (RR1/RR0)

\begin{tabular}{|c|c|c|c|c|c|c|c|c|}
\hline & \multirow{4}{*}{ MAAA } & \multicolumn{3}{|c|}{ Reference group } & \multicolumn{3}{|c|}{ CME Participating group } & \multirow{4}{*}{$\begin{array}{l}\text { Comparison } \\
\text { between } \\
\text { groups } \\
\text { RR1/RRO }\left(p^{*}\right)\end{array}$} \\
\hline & & \multicolumn{3}{|l|}{$N=121$} & \multicolumn{3}{|l|}{$N=81$} & \\
\hline & & Before & After & Before vs. after & Before & After & Before vs. after & \\
\hline & & $\%(n)$ & $\%(n)$ & $\operatorname{RRO}\left(p^{*}\right)$ & $\%(n)$ & $\%(n)$ & RR1 $\left(p^{*}\right)$ & \\
\hline $\begin{array}{l}\text { What is the likelihood that a 50-year-old } \\
\text { patient having cancer at the time you } \\
\text { choose to refer the patient to a cancer } \\
\text { fast-track pathway? }\end{array}$ & $2-10 \%$ & $29.8(36)$ & $38.8(47)$ & $1.31(<0.001)$ & $23.5(19)$ & $65.4(53)$ & $2.79(<0.001)$ & $2.13(0.009)$ \\
\hline $\begin{array}{l}\text { What is the likelihood that a patient } \\
\text { aged } 40 \text { years or more, who is smoker, } \\
\text { has lung cancer the second time s/he } \\
\text { presents with haemoptysis in your } \\
\text { practice? }\end{array}$ & $5-20 \%$ & $33.1(40)$ & $34.7(42)$ & $1.05(0.698)$ & $33.3(27)$ & $58.0(47)$ & $1.74(\mathbf{0 . 0 1 0})$ & $1.63(0.160)$ \\
\hline $\begin{array}{l}\text { What is the likelihood that a patient } \\
\text { aged } 40 \text { years or more has colorectal } \\
\text { cancer the first time that s/he presents } \\
\text { with unintended weight loss and new } \\
\text { onset of constipation in your practice? }\end{array}$ & $2-6 \%$ & $8.3(10)$ & $9.9(12)$ & 1.19 (0.039) & $6.2(5)$ & $28.4(23)$ & $4.6(<0.001)$ & $3.83(0.055)$ \\
\hline $\begin{array}{l}\text { What is the likelihood that a lung } \\
\text { cancer cannot be detected on a chest } \\
x \text {-ray at the time of diagnosis? }\end{array}$ & $\geq 15 \%$ & $81.8(99)$ & $86.0(104)$ & $1.05(0.741)$ & $76.5(62)$ & $81.5(66)$ & $1.06(0.243)$ & $1.07(0.309)$ \\
\hline $\begin{array}{l}\text { What is the proportion of patients with } \\
\text { colorectal cancer who presented an } \\
\text { alarm symptom as the first sign of the } \\
\text { disease to his/her general practitioner? }\end{array}$ & $\leq 60 \%$ & $81.8(99)$ & $86.0(104)$ & $1.05(0.449)$ & $82.7(67)$ & $90.1(73)$ & $1.09(\mathbf{0 . 0 0 6 )}$ & $1.04(0.614)$ \\
\hline $\begin{array}{l}\text { What is the proportion of patients with } \\
\text { ovarian cancer who can be detected } \\
\text { by a pelvic examination (palpation) in } \\
\text { general practice at the time of diagnosis? }\end{array}$ & $\leq 41 \%$ & $90.0(110)$ & $94.2(114)$ & $1.04(0.078)$ & $85.2(69)$ & $92.6(75)$ & $1.09(\mathbf{0 . 0 1 2})$ & $1.05(0.322)$ \\
\hline
\end{tabular}

Bold $=$ significance level of $p \leq 0.05 .{ }^{*}$ corrected for clustering at the study-step-level 
Table 4 The CME effect on GPs' self-assessed readiness to investigate. The proportions of vignettes where the GP made a definitive action after first or second phase of the vignette; one month before (Before) and seven months after (After) the CME. GPs are divided into two groups: CME-participating group and reference group. An effect within a group is shown as an odds ratio (ORO for the Reference group; OR1 for the CME-participating group). Comparisons between groups are shown as a ratio of odds ratios (OR1/OR0)

\begin{tabular}{|c|c|c|c|c|c|c|c|}
\hline & \multicolumn{2}{|c|}{$\begin{array}{l}\text { Reference group } \\
N \text { (vignettes) }=232 \\
N(G P s)=116 \\
\end{array}$} & \multirow{3}{*}{$\begin{array}{l}\text { Before vs. after } \\
\text { ORO* }^{*}(p)\end{array}$} & \multicolumn{2}{|c|}{$\begin{array}{l}\text { CME-participating group } \\
N \text { (vignettes) }=160 \\
N(\text { GPs })=80\end{array}$} & \multirow{3}{*}{$\begin{array}{l}\text { Before vs. after } \\
\mathrm{OR}^{*}(\mathrm{p})\end{array}$} & \multirow{3}{*}{$\begin{array}{l}\text { Comparison } \\
\text { between } \\
\text { groups } \\
\text { OR1/OR0* } \\
\text { (p) }\end{array}$} \\
\hline & Before & After & & Before & After & & \\
\hline & $\%(n)$ & $\%(n)$ & & $\%(n)$ & $\%(n)$ & & \\
\hline Definitive action, at the end of first phase & $37.9(88)$ & $40.1(93)$ & $1.19(0.444)$ & $36.9(59)$ & $43.8(70)$ & $1.70(0.055)$ & $1.43(0.316)$ \\
\hline Definitive action, at the end of second phase & $77.2(179)$ & $77.6(180)$ & $1.04(0.872)$ & $81.9(131)$ & $88.8(142)$ & $2.02(0.043)$ & $1.94(0.119)$ \\
\hline
\end{tabular}

Bold = significance level of $p<0.05$. *adjusted for a study-step and type of vignette

naturalistic experiment. Randomisation at an individual GP level was considered unfeasible due to interaction of GPs within practices. Furthermore, it was preferred to invite all GPs from one cluster to the same CME meeting because geographical acceptability had high priority, and two meetings in each cluster area was found unfavourable due to financial and time costs.

A principal strength is the well-defined study population of GPs described by age, gender and clinic type. Other factors of interest could have been the sociodemographic characteristics of the patient population.

The geographical clusters were divided into CMEparticipating and reference GPs based on the GP's choice of participation. Spill-over effect from the CMEparticipating GPs to the reference GPs could have underestimated the actual effect of the CME. Other initiatives could also have influenced the change from baseline to follow-up, although no competitive regional courses were offered in the study period. We attempted to correct for influence of calendar time by including study steps into the modelling of data.

A major strength is the standardised CME with a detailed description of CME elements, training process and context, which will allow primary health care settings elsewhere to use our findings and adapt them to their context.
Data was collected through a questionnaire developed ad hoc to assess the effect of the CME. The questionnaire included single items specifically targeting the content of the CME. This adaptation may be a potential weakness compared with instruments with established measurement properties, but we found it necessary because relevant validated measures were sparse. The questionnaire was developed in consideration of qualitative and quantitative pilot studies [9]. As paired items were analysed before and after the CME, the possible bias from using ad hoc items was diminished.

The vignettes were developed and validated in an international primary care setting (ICBP-M3) [20, 25]. Evidence suggests that using vignettes in a survey correlates well in clinical practice [26]. The GPs were aware that the questionnaires aimed to evaluate a CME in early cancer diagnosis, and their responses might have been different in a blinded study. Such potential information bias may affect both baseline and follow-up responses in each of the two GP groups, but it is difficult to assess in which direction this may have affected the findings.

A limitation of the study is the modest response rate. As a consequence, selection bias may also affect the findings. We found evidence of such selection bias, but the effect is difficult to establish. Another limitation is

Table 5 The CME effect on GP cancer risk assessment when referring consecutive patients for urgent referral. The numbers of assessing GPs and assessed patients are shown together with the median (inter quartile interval (IQI)) and the mean (95\% Cl) assessed risk of cancer before and after the CME. GPs are divided into two groups: CME-participating group and reference group. An effect within a group and comparisons between groups are shown as regression coefficients

\begin{tabular}{|c|c|c|c|c|c|c|c|}
\hline & \multicolumn{3}{|l|}{ Reference group } & \multicolumn{3}{|c|}{ CME-participating group } & \multirow{4}{*}{$\begin{array}{l}\text { Comparison } \\
\text { between } \\
\text { groups } \\
\text { Regression } \\
\text { coefficient* (p) }\end{array}$} \\
\hline & \multicolumn{3}{|l|}{$N=634$} & \multicolumn{3}{|l|}{$N=197$} & \\
\hline & \multirow[t]{2}{*}{ Before } & \multirow[t]{2}{*}{ After } & Before vs. after & \multirow[t]{2}{*}{ Before } & \multirow[t]{2}{*}{ After } & \multirow{2}{*}{$\begin{array}{l}\text { Before vs. after } \\
\text { Regression } \\
\text { coefficient * }(p)\end{array}$} & \\
\hline & & & $\begin{array}{l}\text { Regression } \\
\text { coefficient* }^{*}(p)\end{array}$ & & & & \\
\hline GPs (n (\%)) & $384(60.6)$ & $364(57.4)$ & & $148(75.1)$ & $160(81.2)$ & & \\
\hline Patients (n) & 1740 & 1276 & & 610 & 838 & & \\
\hline Median risk (\% (|QQI)) & $30(10-50)$ & $30(10-50)$ & & $30(10-50)$ & $15(10-50)$ & & \\
\hline Mean risk (\% (95 \% Cl)) & $39.6(38.1 ; 41.0)$ & $38.8(37.1 ; 40.4)$ & $-0.17(0.063)$ & $39.0(36.6 ; 41.4)$ & $27.4(25.6 ; 29.3)$ & $-1.10(<0.001)$ & $-0.93(<0.001)$ \\
\hline
\end{tabular}

Bold = significance level of $p<0.05$. *adjusted for a study-step and patient's gender and age, on square root scale 
the low participation in the CME. GPs may generally select educational activities in areas of their interest and thus may already perform well in these areas [27]. Nevertheless, in this study, the reference GPs tended to response more appropriately at baseline, but we found no statistically significantly differences between the two groups when comparing the baseline responses.

Apart from GP knowledge and referral threshold, the GP-assessed cancer risk of an urgently referred patient depends on e.g. suspected cancer type, symptom severity, symptom duration and genetic disposition for cancer in combination with patient's age and gender. As we included nearly 4,500 urgently referred patients and adjusted for patient age and gender, the lack of adjustment can be neglected due to an equal variation of patients in each of the two GP groups both before and after the CME. The strategy of reminding the GPs of possible urgent referrals every second week on the basis of hospital registers ensured data completeness. Before being reminded, the reference GPs completed $40.0 \%$ before and $38.6 \%$ after the CME of the one-page forms, whereas the CME-participating GPs completed $47.2 \%$ before and $50.2 \%$ after the CME (not reported in the tables). Recall bias may have occurred when GPs were reminded as a later response may mean that the result of the investigation was known. However, the propensities of the prospective data were almost unchanged from before to after within group. Between groups, misclassification may exist as reference GPs responded less prospectively than the CME-participating GPs which may tend to underestimate the CME-effect.

The national strategy to improve early diagnosis of cancer included a lowering of the GPs' threshold for referring patients for further investigation. Our study indicated such an effect of the CME, which improved the GP-assessed cancer risk of a patient suspected for cancer at the time of referral. As the GPs had high baseline knowledge on diagnostic pitfalls and initial cancer presentation, the ceiling effect made it difficult to demonstrate an effect. Improvements may still be clinically relevant but the ceiling needs to be taken into account when deciding on interventions strategies, including considerations of making such CME activities compulsory.

\section{Comparison with other studies}

To our knowledge, our study is the first to evaluate a comprehensive and primary-care-based intervention on knowledge, attitudes and intended behaviour related to earlier cancer diagnosis, with the same participants and intervention. However, some studies have assessed parts of our intervention. The use of RATs in general practice was evaluated in the UK and was associated with increased diagnostic activity [28]. In Denmark, the use of
RAT for lung cancer as part of a CME was associated with increased referral rate to direct chest CT scan [29]. It is unknown whether the effect found in our study may persist over time. Still, the follow-up of 7 months is longer than in many other studies of educational effects [12].

\section{Conclusion}

The CME lowered the GP-assessed cancer risk of urgently referred patients and showed a limited effect on GPs' knowledge about cancer diagnosis and attitude towards own role in cancer detection; the CME had no effect on self-assessed readiness to investigate and GPs' attitude towards practical aspects of urgent referral. A standardised CME may be effective in changing both GP attitude and knowledge including risk assessment, which may be drivers for change in the clinical performance.

\section{Additional files}

Additional file 1: Table S1. Evidence for the most appropriate response, the predefined most appropriate response area and the testing area for each of the knowledge items. (PDF $113 \mathrm{~kb}$ )

Additional file 2: Table S2. Description of the vignettes. (PDF $92 \mathrm{~kb}$ )

\section{Abbreviations}

$\mathrm{Cl}$, confidence interval; CME, continuing medical education; GP, general practitioner; ICBP-M3, International Cancer Benchmarking Partnership, Module 3; $|\mathrm{Q}|$, interquartile interval; MAR, most appropriate response; OR, odds ratio; RAT, risk assessment tool; RR, risk ratio; SE, standard error

\section{Acknowledgements}

We thank Rikke Pilegaard and Jens Rubak, hospital-GP liaison advisors, Marianne Lentz, CME supervisor, and Gry Stie, academic coordinator at the Regional Cancer Quality Unit, for their contributions with the operationalisation of the CME programme.

We thank Anne Gammelgaard, specialised consultant at Quality and Informatics, Central Denmark Region, and the four radiology departments in Aarhus, Holstebro, Randers and Viborg for the data on patients referred to a fast-track pathway.

We thank Kaare Rud Flarup, data manager at the Research Unit for General Practice at Aarhus University, for creating the database, John Archibald, director of operations at Sigmer Technologies, for designing the online questionnaire and the ICBP Central Team for reuse of the vignettes. We thank the general practitioners from the Central Denmark Region who generously contributed with their time and experience to this study.

\section{Funding}

The project was supported by the Central Denmark Region Foundation for Primary Health Care Research (Praksisforskningsfonden), the Committee for Quality Improvement and Continuing Medical Education (KEU) of the Central Denmark Region, the Multi-Practice Committee (MPU) of the Danish College of General Practitioners (DSAM), the Danish Cancer Society and the Novo Nordisk Foundation. The sponsoring organisations were not involved in any part of the study.

\section{Availability of data and material}

The datasets analysed during the current study are stored in a secured research database and may be available upon presentation of formal approval.

\section{Authors' contributions}

BST, PV and FB planned the design of the study. BST conducted the data collection. AZF and BST performed the statistical analyses. BST wrote the first draft of the article. PV, FB and AZF critically reviewed the article and 
provided comments to improve the manuscript. All authors have read and commented on the final manuscript.

\section{Authors' information}

1. PhD Fellow Berit Skjødeberg Toftegaard, MD, GP. Employed at the Research Centre for Cancer Diagnosis in Primary Care (CaP), Research Unit for General Practice, Department of Public Health, Aarhus University, Bartholins Allé 2, DK-8000 Aarhus C, Denmark

2. Professor Flemming Bro, PhD, MD, GP, Head of Research Unit for General Practice, Department of Public Health, Aarhus University, Bartholins Allé 2 DK-8000 Aarhus C, Denmark

3. Statistician Alina Zalounina Falborg, PhD. Employed at the Research Centre for Cancer Diagnosis in Primary Care (CaP), Research Unit for General Practice, Department of Public Health, Aarhus University, Bartholins Allé 2, DK-8000 Aarhus C, Denmark

4. Professor Peter Vedsted, PhD, MD, Head of Research Centre for Cancer Diagnosis in Primary Care (CaP), Research Unit for General Practice, Department of Public Health, Aarhus University, Bartholins Allé 2, DK-8000 Aarhus C, Denmark

\section{Competing interests}

PV was lecturer at seven CME meetings; FB was lecturer at one CME meeting. The authors declare to have no conflicts of interest.

\section{Consent for publication}

Not applicable.

\section{Ethics approval and consent to participate}

The Danish Committee on Health Research Ethics concluded that no approval or consent to participate was necessary (file. no. 10/2014). The study was approved by the Danish Data Protection Agency (file no. 2009-41-3471). The Danish Health and Medicines Authority gave legal permission to obtain information from the GPs' medical records without permission from the patients (file no. 3-3013-149/1/HKR). The Data Protection Agency in Central Denmark Region gave permission to use the patient administrative system for hospital care to obtain information on patients investigated in a cance fast-track pathway (file no. 1-16-02-262-12). The study is registered as NCT02069470 on ClinicalTrials.gov.

\section{Author details}

${ }^{1}$ Research Unit for General Practice, Department of Public Health, Aarhus University, Bartholins Allé 2, DK-8000 Aarhus, Denmark. ${ }^{2}$ Research Centre for Cancer Diagnosis in Primary Care (CaP), Department of Public Health, Aarhus University, Bartholins Allé 2, DK-8000 Aarhus, Denmark. ${ }^{3}$ Section for General Medical Practice, Department of Public Health, Aarhus University, Bartholins Allé 2, DK-8000 Aarhus, Denmark.

\section{Received: 15 December 2015 Accepted: 20 July 2016}

\section{Published online: 26 July 2016}

\section{References}

1. Torring ML, Frydenberg M, Hamilton W, Hansen RP, Lautrup MD, Vedsted P. Diagnostic interval and mortality in colorectal cancer: U-shaped association demonstrated for three different datasets. J Clin Epidemiol. 2012;65(6):669-78.

2. van Harten MC, Hoebers FJ, Kross KW, van Werkhoven ED, van den Brekel MW, van Dijk BA. Determinants of treatment waiting times for head and neck cancer in the Netherlands and their relation to survival. Oral Oncol. 2015;51(3):272-8.

3. Hansen RP, Vedsted P, Sokolowski I, Sondergaard J, Olesen F. Time intervals from first symptom to treatment of cancer: a cohort study of 2,212 newly diagnosed cancer patients. BMC Health Serv Res. 2011;11(1):284.

4. Probst HB, Hussain ZB, Andersen O. Cancer patient pathways in Denmark as a joint effort between bureaucrats, health professionals and politicians-A national Danish project. Health Policy. 2012;105(1):65-70.

5. Allgar VL, Neal RD. Delays in the diagnosis of six cancers: analysis of data from the National Survey of NHS Patients: Cancer. Br J Cancer. 2005;92(11):1959-70.

6. Hamilton W. Cancer diagnosis in primary care. Br J Gen Pract. 2010; 60(571):121-8.

7. Knottnerus JA. Medical decision making by general practitioners and specialists. Fam Pract. 1991;8(4):305-7.
8. Elstein AS, Schwartz A. Clinical problem solving and diagnostic decision making: selective review of the cognitive literature. BMJ. 2002;324(7339):729-32.

9. Toftegaard B, Bro F, Vedsted P. A geographical cluster randomised stepped wedge study of continuing medical education and cancer diagnosis in general practice. Implement Sci. 2014;9(1):159.

10. Michie S, van Stralen MM, West R. The behaviour change wheel: A new method for characterising and designing behaviour change interventions. Implement Sci. 2011;6:42

11. Grol R, Wensing M, Eccles M, Davis D: Improving patient care: The implementation of change in health care. 24 2nd ed. BMJ Books: Wiley-Blackwell; 2013

12. Forsetlund L, Bjorndal A, Rashidian A, Jamtvedt G, O'Brien MA, Wolf F, Davis D, Odgaard-Jensen J, Oxman AD. Continuing education meetings and workshops: effects on professional practice and health care outcomes. Cochrane Database Syst Rev. 2009:2:CD003030.

13. Hamilton W. The CAPER studies: five case-control studies aimed at identifying and quantifying the risk of cancer in symptomatic primary care patients. Br J Cancer. 2009;101 Suppl 2:S80-6.

14. Hamilton W, Peters TJ, Bankhead C, Sharp D. Risk of ovarian cancer in women with symptoms in primary care: population based case-control study. BMJ. 2009;339(0959-535):b2998.

15. Stapley S, Sharp D, Hamilton W. Negative chest X-rays in primary care patients with lung cancer. Br J Gen Pract. 2006;56(529):570-3.

16. Quekel LG, Kessels AG, Goei R, van Engelshoven JM. Miss rate of lung cancer on the chest radiograph in clinical practice. Chest. 1999;115(3):720-4.

17. Vedsted $\mathrm{P}$, Olesen $\mathrm{F}$. Are the serious problems in cancer survival partly rooted in gatekeeper principles? An ecologic study. Br J Gen Pract. 2011; 61(589):508-12.

18. Rubin G, Vedsted P, Emery J. Improving cancer outcomes: better access to diagnostics in primary care could be critical. Br J Gen Pract. 2011; 61(586):317-8.

19. Pedersen KM, Andersen JS, Sondergaard J. General practice and primary health care in Denmark. J Am Board Fam Med. 2012;25 Suppl 1:S34-8.

20. Rose PW, Hamilton W, Aldersey K, Barisic A, Dawes M, Foot C, Grunfeld E, Hart N, Neal RD, Pirotta M, Sisler J, Thulesius H, Vedsted P, Young J, Rubin G, ICBP Module 3 Working Group*. Development of a survey instrument to investigate the primary care factors related to differences in cancer diagnosis between international jurisdictions. BMC Fam Pract. 2014;15(1): 122. $-2296-15-122$

21. Vedsted P, Olesen F. A differentiated approach to referrals from general practice to support early cancer diagnosis - the Danish three-legged strategy. Br J Cancer. 2015;112(Suppl):S65-9.

22. Jørgensen CK, Karlsmose B. Validation of automated forms processing. A comparison of Teleform ${ }^{\top}$ with manual data entry. Comput Biol Med. 1998; 28(6):659-67.

23. Wooldridge J. Econometric analysis of cross section and panel data. 1st ed. Cambridge, Massachusetts, 23 London. England: MIT Press; 2010.

24. Fitzmaurice G, Laird N, Ware J. Applied longitudinal analysis. 2nd ed. New York: Wiley; 2004.

25. Rose PW, Rubin G, Perera-Salazar R, Almberg SS, Barisic A, Dawes M Grunfeld E, Hart N, Neal RD, Pirotta M, Sisler J, Konrad G, Toftegaard BS, Thulesius H, Vedsted P, Young J, Hamilton W, ICBP Module 3 Working Group*, ICBP Module 3 Working Group. Explaining variation in cancer survival between 11 jurisdictions in the International Cancer Benchmarking Partnership: a primary care vignette survey. BMJ Open. 2015;5(5):e007212. -2014-007212

26. Peabody JW, Luck J, Glassman P, Jain S, Hansen J, Spell M, Lee M. Measuring the quality of physician practice by using clinical vignettes: a prospective validation study. Ann Intern Med. 2004:141(10):771-80.

27. Sibley JC, Sackett DL, Neufeld V, Gerrard B, Rudnick KV, Fraser W. A randomized trial of continuing medical education. N Engl J Med. 1982; 306(9):511-5.

28. Hamilton W, Green T, Martins T, Elliott K, Rubin G, Macleod U. Evaluation of risk assessment tools for suspected cancer in general practice: a cohort study. Br J Gen Pract. 2013;63(606):e30-6.

29. Guldbrandt LM, Rasmussen TR, Rasmussen F, Vedsted P. Implementing direct access to Low-dose computed tomography in general practice-method, adaption and outcome. PLoS One. 2014;9(11):e112162. 